\title{
CARACTERIZAÇÃo DE MISTURAS DE ÓLEO DIESEL COM ÓLEO DE PINHÃO MANSO PARA ACIONAMENTO DE UM TRATOR AGRÍCOLA
}

Wagner da Cunha Siqueira ${ }^{1}$, Haroldo Carlos Fernandes ${ }^{2}$, Anderson Candido da Silva ${ }^{3}$, Mauri Martins Teixeira ${ }^{4}$, Selma Alves Abrahão

\section{RESUMO}

Objetivou-se, com este trabalho, caracterizar misturas de óleo diesel (OD) com óleo de pinhão manso (OPM) e avaliar o desempenho da tomada de potência de um trator agrícola alimentado com estas misturas. Para a caracterização das misturas foram analisadas: massa específica, índice de viscosidade, teor de água, índice de acidez, cinzas sulfatadas e estabilidade oxidativa. Após as análises, verificou-se, por meio de ensaios dinamométricos, o desempenho do motor alimentado com misturas de OD com OPM, em diferentes proporções. As principais conclusões deste trabalho foram: somente os resultados das cinzas sulfatadas atenderam a ANP $n^{\circ} 7$ de 2008. A potência máxima encontrada, 31,93 $\mathrm{kW}$, foi verificada na mistura contendo $75 \%$ de OPM . A mudança de combustível provocou variação no torque e no consumo específico do trator e para todas as misturas em estudo, a reserva de torque foi de $1,75 \%$, classificada como ruim.

Palavras-chave: combustível, desempenho, óleo vegetal

\section{ABSTRACT}

\section{CHARACTERIZATION OF DIESEL OIL BLENDS WITH Jatropha OIL TO POWER A FARM TRACTOR}

The aim of this work was to characterize blends of diesel oil (OD) with jatropha oil (OPM) and evaluate the performance of the power output of an agricultural tractor. For characterization of the mixtures the following parameters were analyzed: specific gravity, viscosity, water content, acid index, sulfated ash, and oxidative stability. After analysis, the dynamometer tests indicatedthe performance of the engine fed with blends of OD and OPM, in different proportions. The main conclusions of this work were: only the results of sulfated ash meet the regulations of ANP No. 7, 2008, and the maximum power encountered, $31.93 \mathrm{~kW}$, was observed for the blend of 25\% OD and 75\% OPM. The change of fuel caused variation in the torque and specific consumption of the tractor and for all mixtures studied the torque reserve was $1.75 \%$, classified as bad.

Keywords: fuel, performance, vegetable oil

Recebido para publicação em 20/08/2013. Aprovado em 15/10/2014.

1 - Eng. Agrícola, Professor - IFMT, Cáceres - MT, wagner.cunha@cas.ifmt.edu.br

2 - Eng. Agrícola, Professor Associado, DEA/UFV, Viçosa-MG, haroldo@ufv.br

3 - Eng. Agrônomo, Mestrando em Engenharia Agrícola, UFV, Viçosa - MG, andersoncandido@hotmail.com

4 - Eng. Agrônomo, Professor Associado, DEA/UFV, Viçosa-MG, mauri@ufv.br

5 - Eng. Agrimensor, Profa. - IFMT, Cáceres - MT, selma.abrahao@cas.ifmt.edu.br.

\section{REVENG}




\section{INTRODUÇ̃̃O}

O desenvolvimento de fontes energéticas é considerado fator estratégico para uma nação e a extensão do uso da energia sempre esteve diretamente associada ao grau de desenvolvimento dos povos. Ao longo da história, pode-se constatar que a disponibilidade e a acessibilidade que as pessoas têm à energia estão ligadas ao crescente conforto humano e à produção de bens (RABELO, 2001). Sem energia, as máquinas param, não há produção, emprego ou renda (YOKOMIZO, 2003).

Vidal (2009) prevê que os óleos vegetais irão substituir o petróleo, dando maior autonomia ao produtor rural, uma vez que promovem o desenvolvimento socioeconômico regional e reduzem as emissões de poluentes. Recentemente, foi constatado que as sementes do pinhão manso produzem um óleo de excelente qualidade, superior ao óleo de mamona e semelhante ao óleo Diesel, extraído do petróleo, podendo assim ser usado como combustível (BANAPURMATH et al., 2008; SIRISOMBOONA et al., 2007). Num motor Diesel, para gerar a mesma potência, o consumo de óleo de pinhão manso foi $16,1 \%$ maior, o ruído mais suave e a emissão de fumaça semelhante (PINHÃO MANSO, 2012).

O emprego direto de óleos vegetais em motores de combustão interna, apesar de experimentado desde o advento do motor Diesel, ainda está sujeito a muitas discussões e controvérsias. As primeiras alusões a respeito de sua eficiência como combustível vêm do início do século, desde a Exposição Universal de Paris (MACHADO, 2003).

A avaliação da qualidade de óleos vegetais, bem como do biodiesel, é de extrema relevância e requer a determinação de suas propriedades físicas e químicas como: massa específica, viscosidade, teor de água, índice de acidez, cinzas sulfatadas e estabilidade oxidativa.

Diante do exposto, objetivou-se com este trabalho, caracterizar misturas de óleo Diesel (OD) com óleo de pinhão manso (OPM) e avaliar o desempenho de um trator agrícola alimentado com estes combustíveis.

\section{MATERIAL E MÉTODOS}

O trabalho foi realizado no Laboratório de Mecanização Agrícola (LMA), pertencente ao Departamento de Engenharia Agrícola (DEA), da Universidade Federal de Viçosa (UFV). Foi realizada a caracterização do óleo Diesel, biodiesel de pinhão manso e de três misturas, com diferentes proporções entre esses dois combustíveis, contendo 25, 50 e $75 \%$ de óleo Diesel. Além da caracterização das misturas foi avaliado o desempenho de um trator agrícola de pneus, marca Valmet, modelo 65ID, alimentado com os cinco combustíveis acima citados.

O óleo de Pinhão Manso (OPM) passou pelos processos de decantação e filtragem para retirada de impurezas e partículas indesejáveis possibilitando seu uso nas misturas com o óleo Diesel.

As misturas foram dosadas com base em massa e não em volume, devido a diferença de massa específica entre o óleo Diesel e o óleo de pinhão manso. Após pesadas, as misturas foram armazenadas em recipientes de cinco litros devidamente identificados.

Para determinação do consumo específico de combustível é necessário conhecer a massa específica dos diferentes combustíveis utilizados. Foi utilizada uma proveta com capacidade de $100 \mathrm{~mL}$ e precisão de $1 \mathrm{~mL}$, um termômetro com variação de $0{ }^{\circ} \mathrm{C}$ a $210{ }^{\circ} \mathrm{C}$ e uma balança com capacidade para $300 \mathrm{~g}$ e precisão de $0,001 \mathrm{~g}$.

A determinação da massa específica iniciou com a pesagem dos combustíveis e medição da temperatura da amostra, $(55 \mathrm{~mL}$ de volume em temperatura ambiente). Esta amostra foi aquecida até $120^{\circ} \mathrm{C}$ e o início do registro das leituras ocorreu quando a temperatura do combustível atingiu 90 ${ }^{\circ} \mathrm{C}$. A cada $5{ }^{\circ} \mathrm{C}$ de decréscimo na temperatura foi coletado o valor de sua massa e volume até que combustível retornasse à temperatura ambiente.

Para a utilização do óleo vegetal in natura em motor Diesel, são necessárias algumas técnicas e adaptações para melhorar o desempenho destes motores, entre elas o aquecimento do óleo para a redução da viscosidade, uma vez que esta tem um valor superior ao óleo Diesel. Para a obtenção das temperaturas no sistema de alimentação de combustível, foram utilizados quatro termopares do tipo $\mathrm{K}$, instalados no tanque de combustível, na entrada e saída da bomba injetora e na entrada do bico injetor, sendo as leituras efetuadas por um termômetro digital conectado a um sistema de aquisição de dados.

$\mathrm{Na}$ análise de viscosidade dos combustíveis foi utilizado um viscosímetro de orifício do tipo Saybolt. A conversão da unidade da viscosidade de Segundos Universais Saybolt (SUS) para Viscosidade Cinemática (Centistokes) foi realizada usando Nomograma (BARGER et al, 1966) posteriormente, os valores foram confrontados com 
as Portarias ANP 310 (2001) e ANP N7 (2008).

As temperaturas em que foi analisada a viscosidade dos combustíveis foram 30,60 e $90{ }^{\circ} \mathrm{C}$ de acordo com a variação da temperatura encontrada no sistema de alimentação de combustível em avaliações anteriores.

Os testes de calorimetria foram realizados utilizando uma bomba calorimétrica marca The Parr, Automatic Adiabatic Calorimeter pertencente ao Departamento de Engenharia Florestal da Universidade Federal de Viçosa. Para a determinação do poder calorífico superior (PCS), os testes seguiram a norma ANSI/ASTM D 240- 76. A

As análises do teor de água, índice de acidez e cinzas sulfatadas foram realizadas pelo Laboratório da Central Analítica de Combustíveis (CEANC) da Universidade Federal do Mato Grosso (UFMT). A análise de estabilidade oxidativa foi realizada no laboratório de melhoramento, biotecnologia e pós-colheita do Departamento de Fitotecnia, pertencente à Universidade Federal de Viçosa. Os métodos utilizados nas análises acima citadas são apresentados no Quadro 1.

Quadro 1. Métodos utilizados para análises do teor de água, cinzas sulfatadas, índice de acidez e estabilidade oxidativa

\section{Característica}

Teor de água $\left(\mathrm{mg} \mathrm{kg}^{-1}\right)$

Índice de acidez $\left(\mathrm{mg} \mathrm{g}^{-1} \mathrm{KOH}\right)$

Cinzas Sulfatadas ( $\%$ massa $)$

Estabilidade Oxidativa (horas)

A avaliação de desempenho do trator agrícola alimentado com os cinco combustíveis foi realizada em dinamômetro de rotação do tipo transmissão montado em berço, sendo seu acoplamento ao trator feito por meio de um eixo cardã.

Além do dinamômetro, foram utilizados: fluxômetro de combustível, com capacidade para $1.000 \mathrm{~mL}$, tacômetro digital e de contato, cronômetro digital e célula de carga com capacidade máxima de 2,5 kN acoplada ao dinamômetro para obter maior precisão na leitura das cargas aplicadas. As avaliações seguiram a norma NBR 5484 (1985), utilizando dados de temperaturas de bulbo úmido, temperatura de bulbo seco e pressão atmosférica, obtida junto ao Instituto Nacional de Meteorologia (INMET).
$\mathrm{Na}$ avaliação foram coletados os dados: rotação do motor, carga aplicada pelo dinamômetro, consumo de combustível e variação da temperatura no sistema de alimentação de combustível e de arrefecimento do motor. Esses dados foram utilizados para determinação dos valores de potência, torque, consumo horário e consumo específico de combustível em função da rotação do motor.

Os dados foram tabulados com auxílio de planilha eletrônica, sendo convertidos e corrigidos de acordo com a norma NBR 5484 (1985).

$\mathrm{O}$ experimento foi conduzido no esquema de parcelas subdivididas segundo o delineamento inteiramente casualisado (DIC) para o ensaio na TDP, com sete cargas $(\mathrm{C} 1, \mathrm{C} 2, \mathrm{C} 3, \mathrm{C} \ldots, \mathrm{C} 7)$, variando de 44,5 a 1.289,9 N (10 a 290 lbf), cinco combustíveis (M1, M2,M..., M5) e cinco repetições.

Seguindo a norma NBR 5484 (1985), as cargas (C1, C2, C..., C7) não foram sorteadas, e sim aplicadas de forma crescente. Sendo assim, o fator mistura foi designado às parcelas e o fator cargas foi designado às subparcelas do experimento. Os dados foram submetidos à análise de variância e aplicação do teste de Tukey em cada carga aplicada para identificar a mistura que proporciona os melhores resultados nas variáveis de interesse.

\section{RESULTADOS E DISCUSSÃO}

Foram ajustados modelos de regressão linear do $1^{\circ}$ grau para estimar a massa específica nas diferentes temperaturas em que o combustível foi submetido $\left(25\right.$ a $\left.90^{\circ} \mathrm{C}\right)$. As equações podem ser visualizadas no Quadro 2.

Os valores de massa específica dos combustíveis ficaram na faixa de 0,728 a $0,827 \mathrm{~g} \mathrm{~mL}^{-1}$ para temperaturas variando de 25 a $90{ }^{\circ} \mathrm{C}$. Observouse que a massa específica tende a diminuir linearmente com o aumento da temperatura sendo que a mistura com $75 \%$ de óleo Diesel apresentou massa específica mais próxima ao óleo Diesel. Verifica-se também que a taxa de variação da massa específica tende a ser maior em misturas com maior porcentagem de óleo de Pinhão Manso (OPM).

Nas Figuras 1 e 2 mostra-se o comportamento da temperatura nos sistemas de alimentação de combustível e arrefecimento quando são utilizados óleo Diesel e biodiesel de pinhão manso, respectivamente. 
Quadro 2. Modelos gerados para estimativa da massa especifica $\left(\mathrm{g} \mathrm{mL}^{-1}\right)$ das misturas em função da temperatura $\left({ }^{\circ} \mathrm{C}\right)$ do combustível.

\begin{tabular}{lcc}
\hline \multicolumn{1}{c}{ Combustível } & Equações & $\mathbf{R}^{2}$ \\
\hline Biodiesel de OPM & $\mathrm{M}=-0,0007 \mathrm{~T}+0,8451$ & 0,90 \\
Mistura com $75 \%$ de OPM & $\mathrm{M}=-0,0008 \mathrm{~T}+0,8300$ & 0,93 \\
Mistura com $50 \%$ de OPM & $\mathrm{M}=-0,0009 \mathrm{~T}+0,8288$ & 0,96 \\
Mistura com $25 \%$ de OPM & $\mathrm{M}=-0,0009 \mathrm{~T}+0,8182$ & 0,98 \\
Óleo Diesel & $\mathrm{M}=-0,0008 \mathrm{~T}+0,8006$ & 0,95 \\
\hline
\end{tabular}

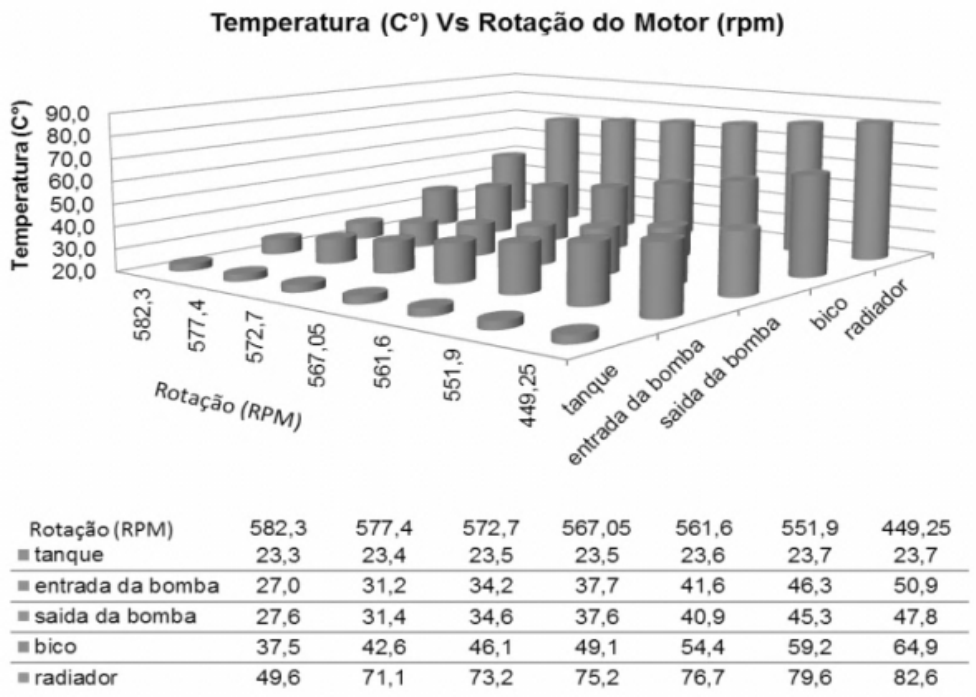

Figura 1. Comportamento da temperatura nos sistemas de alimentação de combustível e arrefecimento utilizando óleo Diesel.

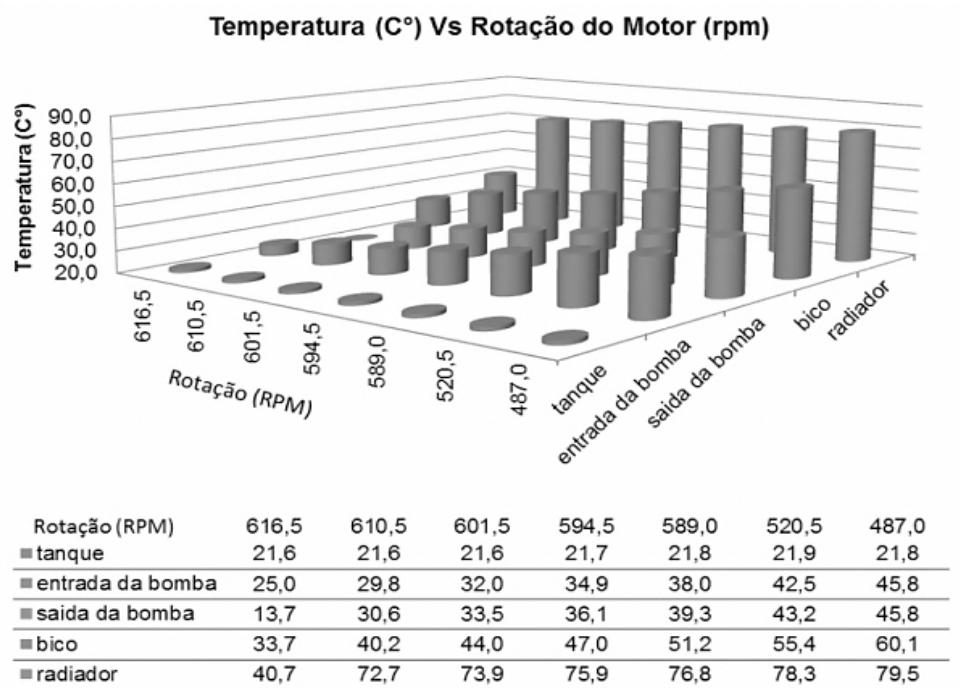

Figura 2. Comportamento da temperatura nos sistemas de alimentação de combustível e arrefecimento utilizando biodiesel de pinhão manso. 
O aumento nas cargas aplicadas na TDP do trator provocou a redução da rotação do motor e aumento da temperatura no sistema de alimentação, implicando na redução da viscosidade do combustível. Também foi constatado aumento da temperatura no bico injetor, que passou de 32,5 para $65,2{ }^{\circ} \mathrm{C}$.

Por meio da análise de regressão foram ajustadas equações para estimar o índice de viscosidade dos combustíveis em uma faixa de temperatura de 30 a $90{ }^{\circ} \mathrm{C}$. Os modelos foram lineares e as estimativas das equações podem ser visualizadas no Quadro 3.

A faixa de viscosidade para o biodiesel, especificada pela ANP $\mathrm{N}^{\circ} 7$ de 2008 , fica entre 3 a $6 \mathrm{cSt}$ à $40^{\circ} \mathrm{C}$. Nenhuma das misturas utilizadas atendeu as exigências de viscosidade do Biodiesel especificada por essa resolução. Esse fato pode ser explicado pelo óleo Diesel ter a viscosidade cinemática perto do limite superior estabelecido pela portaria ANP 310 (2001) (viscosidade entre 2,5 a $5,5 \mathrm{cSt}$ à $\left.40^{\circ} \mathrm{C}\right)$.

Quando a temperatura foi elevada a $85{ }^{\circ} \mathrm{C}$, a viscosidade de todas as misturas testadas se aproximou da faixa exigida pela ANP $N^{\circ} 7$ de 2008. O aquecimento de 25 para $90{ }^{\circ} \mathrm{C}$ do biodiesel de pinhão manso reduziu em até $85 \%$ sua viscosidade.

No Quadro 4 apresentam-se os valores do poder calorífico superior (PCS) dos cinco combustíveis testados.A mistura com $25 \%$ de óleo de pinhão manso apresentou poder calorífico mais próximo ao do óleo Diesel. As misturas com maior proporção de óleo de pinhão manso apresentaram os menores valores de poder calorífico. De maneira geral, o aumento da porcentagem de óleo de pinhão manso nas misturas de combustíveis foi acompanhado pela diminuição do poder calorífico.

Os resultados de teor de água, índice de acidez, cinzas sulfatadas e estabilidade oxidativa são apresentados no Quadro 5.

Tapanes (2008), ao avaliar a produção de biodiesel a partir da transesterificação de óleo de pinhão manso, cita que a qualidade do óleo é medida pelo seu conteúdo de ácidos graxos livres (teor de acidez) e teor de água.

Nos resultados obtidos para o teor de água, somente a mistura com $25 \%$ de óleo de pinhão e o óleo diesel atenderam o valor limite de $500 \mathrm{mg}$ $\mathrm{kg}^{-1}$ estabelecido pela ANP $\mathrm{N}^{\circ} 7$ de 2008. A mistura com $50 \%$ de óleo de pinhão manso apresentou valor muito próximo ao limite e a mistura com $75 \%$ de

Quadro 3. Modelo para a estimativa da viscosidade (cSt) das misturas

\begin{tabular}{lcc}
\hline Combustível & Equação & $\mathbf{R}^{2}$ \\
\hline Biodiesel de OPM & $\mathrm{V}=-0,5813 \mathrm{~T}+61,54$ & 0,94 \\
Mistura com 75\% de OPM & $\mathrm{V}=-0,4327 \mathrm{~T}+44,12$ & 0,84 \\
Mistura com 50\% de OPM & $\mathrm{V}=-0,2260 \mathrm{~T}+24,92$ & 0,89 \\
Mistura com 25\% de OPM & $\mathrm{V}=-0,1340 \mathrm{~T}+15,72$ & 0,82 \\
Óleo Diesel & $\mathrm{V}=-0,0800 \mathrm{~T}+10,08$ & 0,95 \\
\hline
\end{tabular}

Quadro 4. Análise do Poder Calorífico dos combustíveis

\begin{tabular}{lcc}
\hline Combustível & PCS Real $\left(\mathbf{k c a l ~}^{\mathbf{k}} \mathbf{g}^{-1}\right)$ & Ordem de maior PCS \\
\hline Biodiesel de OPM & 9856 & $5^{\circ}$ \\
Mistura com 75\% de OPM & 10173 & $4^{\circ}$ \\
Mistura com 50\% de OPM & 10345 & $3^{\circ}$ \\
Mistura com 25\% de OPM & 10592 & $2^{\circ}$ \\
Óleo Diesel & 10957 & $1^{\circ}$ \\
\hline
\end{tabular}


Quadro 5. Análise do teor de água, índice de acidez, cinzas sulfatadas e estabilidade oxidativa

\begin{tabular}{lcccc}
\hline Característica & $\begin{array}{c}\text { Teor de água } \\
\left(\mathbf{m g ~ k g}^{-1}\right)\end{array}$ & $\begin{array}{c}\text { Índice de acidez } \\
\left(\mathbf{m g ~ g}^{-1} \mathbf{~ K O H}\right)\end{array}$ & $\begin{array}{c}\text { Cinzas sulfatadas (\% } \\
\text { massa) }\end{array}$ & $\begin{array}{c}\text { Estabilidade } \\
\text { oxidativa (horas) }\end{array}$ \\
\hline Biodiesel de OPM & 1046 & 3,16 & 0,019 & 2,86 \\
Mistura com 75\% de OPM & 842 & 1,93 & 0,014 & 0,97 \\
Mistura com 50\% de OPM & 508 & 0,71 & 0,02 & 0,82 \\
Mistura com 25\% de OPM & 323 & 0,46 & 0,016 & 1,76 \\
Óleo Diesel & 113 & 0,11 & 0,002 & - \\
Método & ASTM D 6304 & ASTM D 664 & ABNT NBR 6294 & EN 14112 \\
\hline
\end{tabular}

óleo de pinhão ,assim como o biodiesel de pinhão manso, apresentou valor superior a $500 \mathrm{mg} \mathrm{kg}^{-1}$.

No estabelecimento dos parâmetros de qualidade para aceitabilidade de óleos vegetais é importante que os valores do índice de acidez sejam os menores possíveis, uma vez que elevados valores são indicativos de alterações pronunciadas, comprometendo a capacidade de utilização para fins alimentícios ou carburantes. O monitoramento da acidez dos óleos vegetais também é usado como método auxiliar durante as fases de processamento, estocagem e controle de qualidade. (GALVÃO, 2007).

O óleo de pinhão manso utilizado apresentou valores de índice de acidez acima do limite estabelecido pela ANP $\mathrm{N}^{\circ} 7$ de 2008, sendo que somente a mistura com $25 \%$ de óleo de pinhão manso e o óleo diesel apresentaram valores abaixo de $0,5 \mathrm{mg} \mathrm{g}^{-1}$ de $\mathrm{KOH}$.

Acredita-se que os altos valores de acidez das misturas são devidos às condições como grau de maturação, condições de armazenamento das sementes ou frutos usados para extração da matéria graxa, temperatura e tempo do processo de extração e das condições de armazenagem do óleo. Os valores de índice de acidez das misturas analisadas estão numa faixa de 70 a $100 \%$ do valor máximo permitido, que é de $0,020 \%$, conforme a resolução ANP N ${ }^{\circ} 7$ de 2008.

Em estudos conduzido por Evangelista et al. (2008), os valores encontrados mostraram que o óleo e o biodiesel de pinhão manso estão dentro do valor máximo permitido de $0,020 \%$. O autor afirma que o resultado encontrado para o óleo de pinhão manso é preocupante porque corresponde a $82 \%$ do permitido na norma e, devido à possibilidade de existir erro experimental, pode apresentar valores acima do encontrado. Isto se deve, provavelmente, ao fato do óleo ter diferente teor de ácidos graxos e substâncias insaponificáveis em suas composições. Outra possível explicação seria a possibilidade de resíduos metálicos serem incluídos no processo de moagem da semente antes de se fazer a extração.

Rezende et al.(2006) analisaram a composição de ácidos graxos de vários óleos vegetais e encontraram os seguintes valores de ácidos graxos insaturados: 78, 80,0 e 82,50\% para os óleos de pinhão manso (OPM), soja (OSJ) e algodão (OAG), respectivamente. Enquanto, Santos et al. (2009) descreveu que o teor de ácidos graxos insaturados no óleo de babaçu é de $16,00 \%$. Muitos são os fatores que podem afetar a estabilidade oxidativa dos óleos vegetais, dentre esses, destaca-se a composição de ácidos graxos, exposição à luz e oxigênio.

No presente trabalho, verificou-se que a estabilidade oxidativa não seguiu uma ordem crescente de valores quando se aumenta a porcentagem de óleo de pinhão manso nos combustíveis. Acredita- se que tal comportamento se deve a fatores como maturação, más condições de armazenamento, exposição à luz, variação de temperatura e tempo da extração do óleo de pinhão manso.

No Quadro 6 estão representadas as potências corrigidas para cada uma das misturas de combustíveis. 
Quadro 6. Médias de potência $(\mathrm{kW})$ em cada uma das misturas de combustível

\begin{tabular}{lccccccc}
\hline \multicolumn{7}{c}{ Cargas (N) } \\
\hline Combustível & $\mathbf{4 4 , 4}$ & $\mathbf{2 8 9}$ & $\mathbf{5 3 3}$ & $\mathbf{7 7 8}$ & $\mathbf{1 0 2 3}$ & $\mathbf{1 2 6 7}$ & $\mathbf{1 2 8 9}$ \\
\hline Óleo Diesel & $1,11 \mathrm{a}$ & $7,42 \mathrm{c}$ & $13,93 \mathrm{e}$ & $20,11 \mathrm{e}$ & $26,18 \mathrm{e}$ & $31,87 \mathrm{a}$ & $26,40 \mathrm{~d}$ \\
Mistura com 25\% de OPM & $1,19 \mathrm{a}$ & $7,83 \mathrm{~b}$ & $14,94 \mathrm{~b}$ & $21,59 \mathrm{~b}$ & $28,05 \mathrm{~b}$ & $31,68 \mathrm{~b}$ & $28,84 \mathrm{~b}$ \\
Mistura com 50\% de OPM & $1,2 \mathrm{a}$ & $8,13 \mathrm{a}$ & $15,14 \mathrm{a}$ & $21,91 \mathrm{a}$ & $28,37 \mathrm{a}$ & $28,76 \mathrm{~d}$ & $25,79 \mathrm{e}$ \\
Mistura com 75\% de OPM & $1,19 \mathrm{a}$ & $7,9 \mathrm{~b}$ & $14,64 \mathrm{c}$ & $21,11 \mathrm{c}$ & $27,77 \mathrm{c}$ & $31,93 \mathrm{a}$ & $30,41 \mathrm{a}$ \\
Biodiesel de OPM & $1,23 \mathrm{a}$ & $7,93 \mathrm{~b}$ & $14,43 \mathrm{~d}$ & $20,80 \mathrm{~d}$ & $27,09 \mathrm{~d}$ & $29,66 \mathrm{c}$ & $28,24 \mathrm{c}$ \\
\hline
\end{tabular}

As médias seguidas por pelo menos uma mesma letra minúscula numa mesma coluna, não diferem estatisticamente pelo teste de Tukey a $5 \%$ de significância.

Nas avaliações, a potência máxima encontrada, $31,93 \mathrm{~kW}$, foi verificada na mistura com $25 \%$ de óleo de pinhão manso, porém, este valor não foi significativo quando comparado ao óleo Diesel.

A mudança de combustível provocou variação na potência do motor, sendo que o combustível com $50 \%$ de óleo de pinhão manso obteve em maior parte das cargas, maior potência quando comparado aos demais. Nas duas últimas cargas aplicadas, houve maior variação de potência entre os diferentes combustíveis, sendo que o combustível com $25 \%$ do óleo vegetal apresentou maior potência.

Vitoria et al. (2012) verificou resultados contrários ao apresentado neste trabalho quando comparou o desempenho de um motor utilizando misturas de óleo Diesel e óleo de pinhão manso. Em sua comparação, verificou que houve interação entre as misturas avaliadas, sendo que o combustível com $50 \%$ de óleo de pinhão manso apresentou menor valor de potência em relação às demais misturas avaliadas.

O estudo da variação da potência dentro de carda carga possibilita ao operador escolher qual a melhor mistura que poderá ser utilizada em determinadas operações, onde as cargas aplicadas podem simular uma operação cotidiana das atividades desenvolvida pelo trator. A variação do torque do motor de acordo com as misturas utilizadas pode ser verificada no Quadro 7.

$\mathrm{Na}$ avaliação do torque foi verificada diferença significativa entre os combustíveis. A mudança de combustível provocou variação no torque do motor, sendo que a mistura com $25 \%$ do óleo vegetal apresentou, a partir da carga de $533 \mathrm{~N}$, os maiores valores com relação às demais misturas. Entretanto, o biodiesel de pinhão manso obteve maiores valores entre as cargas de 44,4 e $298 \mathrm{~N}$.

Comportamento semelhante do motor foi observado por Kamarudin et al. (2009) estudando o desempenho do motor Diesel alimentado com óleo bruto de pinhão manso misturado ao óleo Diesel. Os autores vereficaram uma variação do torque, de acordo com a rotação do motor e aumento da porcentagem de óleo de pinhão manso nas misturas, que provocou redução do torque do motor. Os autores atribuem esse resultado às altas viscosidades e densidades das misturas com óleo bruto de pinhão manso que inibem a atomização do combustível.

No Quadro 8 estão representados os dados de consumo específico corrigido para os diferentes combustíveis.

A mudança de combustível provocou variação no consumo específico do motor, sendo que o biodiesel de pinhão manso apresentou o maior consumo específico enquanto que o menor consumo específico foi verificado quando é utilizado o óleo Diesel.

A adição do óleo de pinhão manso provocou variação nos valores de consumo específico de combustível, sendo que na carga de 44,4 $\mathrm{N}$ houve maior variação entre os combustíveis. $\mathrm{Na}$ carga de $533 \mathrm{~N}$, todos os combustíveis que continham óleo Diesel não diferiram entre si, apresentando diferença somente em relação ao biodiesel de pinhão manso. A variação entre o menor consumo 
Quadro 7. Médias do torque para os diferentes combustíveis

\begin{tabular}{lccccccc}
\hline \multicolumn{7}{c}{ Cargas (N) } \\
\hline Combustível & $\mathbf{4 4 , 4}$ & $\mathbf{2 8 9}$ & $\mathbf{5 3 3}$ & $\mathbf{7 7 8}$ & $\mathbf{1 0 2 3}$ & $\mathbf{1 2 6 7}$ & $\mathbf{1 2 8 9}$ \\
\hline Óleo Diesel & $18,18 \mathrm{~b}$ & $122,77 \mathrm{c}$ & $232,22 \mathrm{c}$ & $338,65 \mathrm{c}$ & $445,09 \mathrm{c}$ & $551,52 \mathrm{c}$ & $561,19 \mathrm{c}$ \\
Mistura com 25\% de OPM & $18,22 \mathrm{~b}$ & $121,45 \mathrm{e}$ & $234,01 \mathrm{a}$ & $341,26 \mathrm{a}$ & $448,51 \mathrm{a}$ & $555,77 \mathrm{a}$ & $565,52 \mathrm{a}$ \\
Mistura com 50\% de OPM & $18,18 \mathrm{~b}$ & $123,73 \mathrm{~b}$ & $232,31 \mathrm{~b}$ & $338,79 \mathrm{~b}$ & $445,27 \mathrm{~b}$ & $551,75 \mathrm{~b}$ & $561,43 \mathrm{~b}$ \\
Mistura com 75\% de OPM & $18,11 \mathrm{c}$ & $121,62 \mathrm{~d}$ & $228,64 \mathrm{e}$ & $333,44 \mathrm{e}$ & $438,23 \mathrm{e}$ & $543,02 \mathrm{e}$ & $552,55 \mathrm{e}$ \\
Biodiesel de OPM & $19,00 \mathrm{a}$ & $124,11 \mathrm{a}$ & $229,12 \mathrm{~d}$ & $334,13 \mathrm{~d}$ & $439,14 \mathrm{~d}$ & $544,12 \mathrm{~d}$ & $553,7 \mathrm{~d}$ \\
\hline
\end{tabular}

As médias seguidas pela mesma letra na coluna, não diferem estatisticamente pelo teste de Tukey a $5 \%$ de significância.

Quadro 8. Médias do consumo específico para diferentes misturas de combustíveis

\begin{tabular}{lccccccc}
\hline \multicolumn{7}{c}{ Cargas (N) } \\
\hline Combustível & $\mathbf{4 4 , 4}$ & $\mathbf{2 8 9}$ & $\mathbf{5 3 3}$ & $\mathbf{7 7 8}$ & $\mathbf{1 0 2 3}$ & $\mathbf{1 2 6 7}$ & $\mathbf{1 2 8 9}$ \\
\hline Óleo Diesel & $1673,35 \mathrm{~d}$ & $417,01 \mathrm{c}$ & $316,67 \mathrm{~b}$ & $278,95 \mathrm{~d}$ & $277,11 \mathrm{c}$ & $315,56 \mathrm{c}$ & $384,64 \mathrm{~b}$ \\
Mistura com 25\% de OPM & $1589,44 \mathrm{e}$ & $368,23 \mathrm{~d}$ & $315,37 \mathrm{~b}$ & $281,83 \mathrm{~cd}$ & $283,41 \mathrm{c}$ & $328,32 \mathrm{c}$ & $367,48 \mathrm{c}$ \\
Mistura com 50\% de OPM & $1816,01 \mathrm{c}$ & $437,35 \mathrm{~b}$ & $319,52 \mathrm{~b}$ & $304,65 \mathrm{~b}$ & $306,91 \mathrm{~b}$ & $351,84 \mathrm{~b}$ & $396,11 \mathrm{~b}$ \\
Mistura com 75\% de OPM & $1849,12 \mathrm{~b}$ & $413,19 \mathrm{c}$ & $320,94 \mathrm{~b}$ & $293,86 \mathrm{bc}$ & $301,36 \mathrm{~b}$ & $325,24 \mathrm{c}$ & $344,62 \mathrm{~d}$ \\
Biodiesel de OPM & $2971,40 \mathrm{a}$ & $663,81 \mathrm{a}$ & $510,14 \mathrm{a}$ & $490,05 \mathrm{a}$ & $470,43 \mathrm{a}$ & $525,14 \mathrm{a}$ & $561,56 \mathrm{a}$ \\
\hline
\end{tabular}

As médias seguidas por pelo menos uma mesma letra minúscula numa mesma coluna, não diferem estatisticamente pelo teste de Tukey a $5 \%$ de probabilidade.

específico e o consumo específico apresentado pela maior potência produzida, foi de $48,13 \mathrm{~g} \mathrm{~kW}^{-1} \mathrm{~h}^{-1}$.

Resultado semelhante foi observado por Vitoria et al. (2012) que verificou menor consumo específico em todas as misturas de óleo Diesel com óleo de pinhão manso ocorreu em uma faixa de rotação entre 580 e $600 \mathrm{rpm}$, para uma carga aplicada a TDP de 888 N. Também foi verificado nessa carga o maior valor de consumo específico de combustível para o óleo Diesel. No estudo conduzido, para todos combustíveis, a reserva de torque foi de $1,75 \%$, mantendo na classificação ruim conforme (MIALHE, 1996).

Machado (2008), Volpato et al. (2009) e Costa e Oliveira (2006), conduzindo estudos de desempenho de motores Diesel utilizando biodiesel de óleo vegetal, relataram que a redução da reserva de torque é em função do uso do combustível oriundo do óleo vegetal.

\section{CONCLUSÕES}

- O aumento da concentração de óleo de pinhão manso provoca redução da temperatura no sistema de alimentação de combustível;

- Quando a temperatura foi elevada para $85^{\circ} \mathrm{C}$ a viscosidade de todos os combustíveis testados se aproximaram da faixa de viscosidade exigida pela ANP $\mathrm{N}^{\circ} 7$ de 2008;

- O poder calorífico mais próximo ao do óleo Diesel foi encontrado para a mistura com $25 \%$ de óleo de pinhão manso, sendo que esta apresenta $365 \mathrm{kcal}$ a menos que o óleo Diesel;

- Nos resultado obtidos para o teor de água, somente a mistura com $25 \%$ de óleo de pinhão manso e o óleo diesel atendem o valor limite de $500 \mathrm{mg} \mathrm{kg}^{-1}$ estabelecido pela ANP N ${ }^{\circ} 7$ de 2008; 
- O óleo de pinhão manso utilizado apresentou valores do índice de acidez acima do limite estabelecido pela ANP $N^{\circ} 7$ de 2008;

- As misturas analisadas apresentaram valores de cinzas sulfatas dentro do limite permitido de $0,020 \%$ conforme a resolução ANP $\mathrm{N}^{0} 7$ de 2008 ;

- A estabilidade oxidativa não se enquadrou no limite estabelecido pela ANP $\mathrm{N}^{\circ} 7$ de 2008;

- A potência máxima encontrada, $31,93 \mathrm{~kW}$, foi verificada na mistura com $25 \%$ OD e $75 \%$ OPM;

- A mudança de combustível provocou variação no torque do motor, sendo que a mistura com $25 \%$ de OPM apresentou, a partir da carga de $533 \mathrm{~N}$, os maiores valores de torque;

- O menor consumo específico foi verificado para o óleo Diesel;

- Para todos os combustíveis estudados, a reserva de torque foi de $1,75 \%$, classificada como ruim.

\section{AGRADECIMENTOS}

Os autores agradecem à FAPEMIG, CNPq, Nòvabra Energia - ES , CEANC e ao IFMT campus Cáceres pelo apoio para a realização deste trabalho

\section{REFERÊNCIAS BIBLIOGRÁFICAS}

ASSOCIAÇÃO BRASILEIRA DE NORMAS TÉCNICAS. NBR 5484: Motores alternativos de combustão interna de ignição por compressão (Diesel) ou ignição por centelha (Otto) de velocidade angular variável - ensaio - Método de ensaio. Rio de Janeiro, 1985. 8p.

BANAPURMATH, N.R.; TEWARI, P.G.; HOSMATH, R.S. Performance and emission characteristics of a DI compression ignition engine operated on Honge, Jatropha and sesame oil methyl esters. Renewable Energy, v.33, n.9, p.1982-1988, 2008.

BARGUER, E.L.; LILJEDAHL, J.B.; CARLETON, W.M.; MCKIBBEN, E.G. (1966):
Tratores e seus motores. São Paulo, Edgar Blucher. 398p.

COSTA, B.J.; OLIVEIRA, S.M.M. de. Produção de biodiesel. Dossiê técnico: TECPAR, 27p., 2006. Disponível em: http://www.sbrt.ibict.br/dossiestecnicos . Acesso em: 10 Set. 2012.

GALVÃO, L.P.F.C; Avaliação Termoanalítica da Eficiência de Antioxidantes na Estabilidade Oxidativa do Biodiesel de Mamona. 2007. 159f. Dissertação (Mestrado em Química). Universidade Federal do Rio Grande do Norte, Natal, 2007.

KAMARUDIN, K.A.; SAZALI, N.S.A.M.; ALI, M.F.M.; ALIMIN, A.J.; KHIR, S.A. Performance of diesel engine using blended crude Jatropha oil. In: THE 10TH ASIAN INTERNATIONAL CONFERENCE ON FLUID MACHINERY, 10., 2009, Malaysia. Proceedings... Kuala Lumpur: Malaysia, 2009.

LIMA, L.R.; MARCONDES, A.A. Álcool carburante: uma estratégia brasileira. Curitiba: Ed. UFPR, 2002. 246p.

MACHADO, P.R.M. Avaliação de desempenho do óleo de soja como combustível para motores diesel. 2003. 212f. Dissertação (Mestrado em Engenharia Agrícola). Universidade Federal de Santa Maria, Centro de Ciências Rurais, Santa Maria, 2003.

MACHADO, P.R.M. Ésteres combustíveis em motor de ciclo diesel sob condições de préaquecimento e variação no avanço de injeção. 2008. 142f. Tese (Doutorado em Engenharia Agrícola). Universidade Federal de Santa Maria, Santa Maria, 2008.

MIALHE, L.G., Máquinas agrícolas: Ensaios \& Certificações. Piracicaba, SP: Fundação de estudos agrários Luiz de Queiroz, 1996.

PINHÃO MANSO (Jatropha curcas) - Uma planta do futuro. Disponível em http://www.pinhaomanso.com.br. Acesso em 20 Agosto de 2012. 


\begin{abstract}
RABELO, I.D. Estudo de desempenho de combustíveis convencionais associados a biodiesel obtido pela transesterificação de óleo usado em fritura. 2001. 98f. Dissertação (Programa de Pós-Graduação em Tecnologia) Centro Federal de Educação Tecnológica do Paraná, Curitiba,2001.
\end{abstract}

REZENDE, D.R.; SOUZA, L.F.; NUNES, D.E.B.M.R.; ZUPPA, T.O.; ANTONIOSI FILHO, N.R.. Caracterização de ácidos graxos e triacilglicerídeos de óleos vegetais com potencial econômico de produção de biodiesel na Região Centro-Oeste. In: I Congresso da Rede Brasileira de Tecnologia de Biodiesel, 2006, v.1.

SANTOS, N.A.; SANTOS, J.R.J.; SINFRÔNIO, F.S.M.; BICUDO, T.C.; SANTOS, I.M.G.; ANTONIOSI FILHO, N.R.; FERNANDES JUNIOR, V.J.; SOUZA, A.G. 2009. ThermoOxidative Stability and Cold Flow Properties of Babassu Biodiesel by PDSC and TMDSC Techniques. Journal of Thermal Analysis and Calorimetry. 96, 2009. doi: 10.1007/s10973-0089719-2.

SIRISOMBOONA, P.; KITCHAIYAB, P.; PHOLPHOA, T.; MAHUTTANYAVANITCHA, W., Physical and mechanical properties of Jatropha curcas L. fruits, nuts and kernels. Biosystems
Engineering, v.97, p.201-207, 2007.

TAPANES, N.C.O.; ARANDA, D.A.G.; CARNEIRO, J.W.M.; ANTUNES, O.A.C., Transesterication of Jatropha curcas oil glycerides: Theoretical and experimental studies of biodiesel reaction. Fuel, v.87, p.2286-2295, 2008.

VIDAL, J.W.B. Heranças do petróleo. In: UCZAI, Pedro (Org.). Inevitável Mundo Novo: a relação entre energias renováveis, produção de alimentos e o futuro do planeta. Chapecó: Pallotti, 2009.

VITÓRIA, E.L; OLIVEIRA, P.S; FERNANDES, H.C; LONGUI, F.C; LEITE, D.M. Desempenho comparativo de um motor ciclo Diesel alimentado com misturas de óleo Diesel e biodiesel de pinhãomanso. ENCICLOPÉDIA BIOSFERA, Centro Científico Conhecer - Goiânia, v.8, n.14; p.1865, 2012.

VOLPATO, C.E.S; CONDE, A.P; BARBOSA, J.A; SALVADOR, N. Desempenho de um motor Diesel quatro tempos alimentado com biodiesel de óleo de soja (B100). Ciênc. agrotecnologia., v.33, n.4, p.1125-1130, jul./ago. 2009

YOKOMIZO, E.O combustível do girassol. Revista CREA-PR, ano 6, n.21,p.18-23, fev./mar., 2003. 